The first and larger portion of the book deals with the archæology, ethnology, linguistic divisions, habits, and beliefs of the ancient inhabitants of the present States of Nicaragua, Costa Rica, and Panama. The people belong to the same stock, with modifications, which stretched from the Sonoran region through the whole of Central America far into the western-let us say Andineportion of the southern continent, leaving the bulk of the latter to what may be called the typical neo-tropical races, notably Guarani, Tupi, Arawak, and Caribs. In conformity with the configuration of the isthmus, the influence from the Inca centre was insignificant in comparison with that from the Maya-Mexican. It is the reverse with the fauna and flora, which naturally date from much earlier epochs with broader contact.

The last hundred pages are devoted to the West Indies. These fairest and most fertile islands being subject to earthquakes, volcanic eruptions, and hurricanes, it is, according to our author, not surprising that their inhabitants developed a religious system which consisted in the main of a propitiation of the powers of Nature. Nevertheless, according to the testimony of $\mathrm{C}$. and $\mathrm{F}$. Columbus,

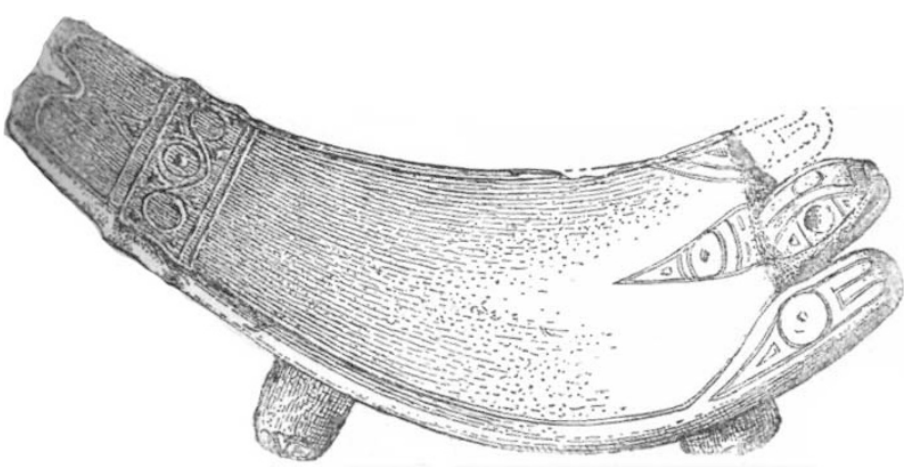

Fig. 2.-Porto Rico: Stone seat. (Scale, one-tilird.) From "Central American and West Indian Archæology."

father and son, they seem to have been a kindly, honest, and generous folk, to whom contact with the Spaniards meant speedy extermination.

The original stock of the whole archipelago were Arawaks from the southern continent, and were in turn followed by the more bellicose Caribs, who at the time of their discovery were in possession of the Lesser Antilles and fast extending into some of the greater islands. They had a patriarchal system, with caciques or small chiefs. A tie of friendship was the mutual exchange of their names. They practised the couvade. The Arawaks were armed with sword-clubs and javelins, hurled by means of ornamented spearthrowers. The chief weapon of the Caribs was the bow. The male prisoners were eaten. There is no evidence that stone weapons were used, the blades of stone found being tools. Charms were made of wood and stone, images of man and animals. Interesting are the stone collars which are said to be the translation into stone of originally a wooden hoop, a tree-fork bent and fixed by bandages into this shape. The enclosing of a spirit in such a circle is connected NO. 2448 , VOL. 98$]$ with tree-worship. Beautiful stone collars are found also in the Maya-Mexican countries.

But there is very little known about such and similar curiosities beyond the often gratuitous accounts of the old chronists, and the same applies to the beliefs and habits of these vaishow porple. Some are no doubt of genuine indigenous origin; others point to the western or to the southern mainland, just as one would expect. Since these islanders used dug-outs, large enough for even lorg voyages, it is not surprising that their kind of civilisation-as shown by their weapons, ornaments, stone masks, figurines, pottery, etc.-was more or less alike all over the archipelago.

\section{THE ABNORMAL PROPAGATION OF} SOUND BY THE ATMOSPHERE.

MR. S. FUJIWHARA has recently published a second valuable memoir on the abnormal propagation of sound-waves in the atmosphere (Bull. Centr. Meteor. Observatory of Japan, vol. ii., r916, pp. I-82). As in his previous paper (NATURe, vol. xcii., I9I4, p. 592), he ascribes the peculiarities investigated to variations of the airtemperature and of the velocity and direction of the wind, and he concludes that the structure of the upper atmosphere may be inferred from the form of the region of audibility.

The present memoir consists of two chapters. The first is theoretical, and deals with the modes of propagation of sound-waves through the atmosphere, the structure of which may be one of the five types observed by Capt. C. J. P. Cave at Ditcham Park, Petersfield, Hants. He shows that the region of audibility, including the sound-source (or proximate region), may in many cases be of triangular, or rather fish-tail, form, the axial direction of which may be not only in the direction of the wind then prevailing, but also in any other direction, at right angles or even opposite to that of the wind; for it depends chiefly on the direction of the wind in the lower stratum of the atmosphere with respect to that at the earth's surface. In other cases the proximate region may assume a spiral form, with the vertex at the source of sound and extending in the sense of the veering of the wind in the upper atmosphere. The regions of audibility due to winds at different heights may overlap one another. Detached regions of audibility may appear in a zone subtending an angle of less than two right angles at the sound-source, and they may be of any form. If the wind remains steady in direction and velocity in the upper layers, or if there is a decrease in velocity in the upper atmosphere, detached regions should not occur. With an increase of velocity in the upper atmosphere, detached regions may occur in the same direction as the proximate region. But if there should be a reversal or great change of direction in the upper layers, or if the upper wind should blow from a distant low-pressure centre with frequent reversal in the lower 
layers, detached regions should be more often present than absent.

In the second chapter Mr. Fujiwhara compares his theoretical investigations with the results of sixty-five explosions during the years rgra and I9I3, for the most part those of the Asama-yama, in Central Japan. These show that the axis of the region of audibility may or may not agree with the direction of the wind at a moderate height; that in some cases the regions of audibility are triangular or spiral in form; that detached regions may occur on the same side of the source, while sometimes a very large detached region may be found in company with a very small one at the source; and, lastly, that detached regions of audibility and a silent region may appear in any direction and at any distance according to the prevailing condition of the weather. In Japan the monsoon exercises a powerful influence on the propagation of sound-waves in the atmosphere, and this accounts for the observed differences in summer and winter. In summer the formation of the detached region of audibility is rather common, and takes place towards the west or south-west of the source, while in winter the phenomenon occurs more rarely and is then caused by an approaching cyclone.

C. Davison.

SIR LAUDER BRUNTON, BT., F.R.S.

$\mathrm{O}^{\mathrm{N}}$ the I6th of the month this distinguished physician passed away after a long illness, borne with rare fortitude. Although retired from private practice, Brunton was far indeed from retirement in respect of those public causes to which, with the pious tenacity of his race, he devoted much of his life, and a fervour almost religious in its depth and constancy. Some weeks before his death the present writer had visited Lauder Brunton, and witnessed both the distress under which he laboured and the ingenious methods he had devised for keeping the evil at bay; not in the desire of a mere prolongation of life, though this indeed were no unworthy intention, but in order to cherish the fire of its last embers for those humane ends which he had so ardently at heart. It was therefore with admiration that, about three weeks before his decease, the writer received from his friend now silent a long and important letter covering certain documents and proposals on the subject of physical education, a movement to which, in his later years, Brunton had given no little energy and guidance, especially for the sake of children and young people, and which he was pressing forward almost with his latest breath. Fortunately, he has worked with comrades and assistants who. will not fail to keep his lamp alight, nor let any of his last counsels be forgotten.

At St. Bartholomew's Brunton proved to be not only a distinguished man of science, but also of much accomplishment and success in the practice of his art. Like James Goodhart of Guy's, who died but a short while before him, he won the faith and attachment of a large clientèle by merit No. 2448, VOL. 98] pure of all self-seeking. Although these great teachers were not quite alike in the ways of their medical observation, yet to the particular skill of each were added kindliness of heart and an earnest sympathy which won the confidence of the sufferers who sought their aid. If Brunton had not the imposing personal presence of certain eminent physicians of the past, no one could speak with him without being affected by his gentle, persuasive enthusiasm, and that faith in his art and in mankind which engendered alike faith and hope in those who only too often sorely needed these blessings.

Lauder Brunton was one of the first of the scientific practising physicians who used no empirical remedies without seeking to discover their mode of action, and by pharmacological and other research endeavoured to add to their number. Bence Jones, Golding Bird, Pavy, were of the generation before him, it is true; but few physicians whose interests before all else were, and still remained, clinical, had likewise followed scientific investigation so systematically and in so disinterested a spirit. Moreover, in his particular departments of science Brunton was a pioneer, especially in pharmacology and in the physics of the circulation. With a mind strengthened by the seriousness and philosophical temper of his great university of Edinburgh, Brunton, after graduation, spent two or three years in foreign study, for the most part in Germany; and no British physician had a better knowledore than he of German teachers, German industry, and of that necessary condition-the German tongue. Thus for him the war was full of sadness.

In this brief tribute no attempt can be made even to indicate the character and extent of Brunton's scientific work, pharmacological, clinical, and hygienic. His contributions are only partially presented, indeed, in the two or three portly octavos in which many of them were recently reprinted. But if to the chief or to the more familiar of his works some allusion may be made, it would be to his researches with Fayrer into venoms-a successful attempt to clarify a very ancient and chequered story, as the historian of medicine well knows; to his part as one of the Commission which reported on Pasteur's treatment of hydrophobia; to his services on the Hyderabad Commission on the effects of chloroform, by which, if its results were doubted in some quarters and in others enlarged, nevertheless the whole problem was raised to the plane of its infinite importance; to his work on tuberculosis, which was informed by the spirit of a social prophet; and to his researches on the dynamics of the circulation. Herein he made the beneficent discovery of the nitrites as palliative, or better than palliative, in that awful malady angina pectoris, a discovery deserving to rank with that of Peruvian bark in the cure of ague. If, as the present writer has remarked elsewhere, ${ }^{1}$ the discovery arose accidentally from

\footnotetext{
1 "Diseases of the Arteries," I915.
} 